\title{
Reactions to a targeted intervention to increase fecal occult blood testing among average-risk adults waiting for screening colonoscopy
}

\author{
S Elizabeth McGregor* PhD 1,2,3, Paul Ritvo* PhD ${ }^{4,5,6,7}$, Jill Tinmouth MD ${ }^{8,9,10}$, Ashley Kornblum BSc ${ }^{4}$, \\ Ronald Myers $\mathrm{PhD}^{11}$, Robert J Hilsden MD PhD ${ }^{2,12}$, Lawrence F Paszat MD 6 ,9,10, Linda Rabeneck MD ${ }^{8,9,10}$
}

SE McGregor, P Ritvo, J Tinmouth, et al. Reactions to a targeted intervention to increase fecal occult blood testing among average-risk adults waiting for screening colonoscopy. Can J Gastroenterol 2011;25(5):248-252.

BACKGROUND: Increasing demand combined with limited capacity has resulted in long wait times for average-risk adults referred for screening colonoscopy for colorectal cancer. Management of patients on these growing wait lists is an emerging clinical issue.

OBJECTIVE: To inform the content and design of a mailed targeted invitation for patients to undergo annual fecal occult blood testing (FOBT) while awaiting colonoscopy.

METHODS: Focus groups (FGs) with average-risk patients on a wait list for screening colonoscopy at a high-throughput academic outpatient colonoscopy facility were conducted. During each FG session, feedback regarding a range of materials under consideration for the planned intervention was elicited using a semistructured facilitator guide. The FG sessions were recorded and transcribed verbatim, and analyzed using the constant comparative method to identify key themes.

RESULTS: Findings from the three FGs $(n=28)$ suggested that averagerisk patients on a wait list for screening colonoscopy would be receptive to a targeted intervention recommending they undergo FOBT while waiting. Participants indicated that the invitation to undergo FOBT was an important acknowledgement that they were on an actively managed list, and that a mechanism to ensure that they were correctly triaged while waiting was in place. Several specific suggestions to improve the design of the targeted intervention were obtained.

CONCLUSIONS: Results of the present study provide useful information for developing effective strategies to manage average-risk individuals facing long wait times for screening colonoscopy.

Key Words: Cancer screening; Colorectal cancer; Fecal occult blood tests; Focus groups

Condo olorectal cancer (CRC) is an important public health problem and the second leading cause of cancer mortality in Canada, with estimates of 22,500 cases and 9100 deaths in 2010 (1). Despite strong evidence that screening reduces CRC incidence and mortality, screening rates are low (2-5). Evidence-based recommendations for physicians (6-8) and professional societies $(9,10)$ have consistently recommended CRC screening for average-risk adults. The Canadian Association of Gastroenterology (11) has supported CRC screening programs with test choices aligned with patient preference, evidence and locally available capacity. Population-based screening programs, implemented to increase screening coverage in several Canadian

\begin{abstract}
Les réactions à une intervention ciblée pour accroître les recherches de sang occulte dans les selles chez des adultes à risque moyen en attente d'une coloscopie de dépistage
\end{abstract}

HISTORIQUE : La demande croissante, associée à une capacité limitée, a entraîné de longs temps d'attente pour les adultes à risque moyen aiguillés vers une coloscopie de dépistage d'un cancer colorectal. La prise en charge des patients figurant sur ces listes d'attente croissantes est un enjeu clinique émergent.

OBJECTIF : Documenter le contenu et la conception d'une invitation ciblée postée aux patients afin qu'ils subissent une recherche de sang occulte dans les selles (RSOS) en attendant une coloscopie.

MÉTHODOLOGIE : Les chercheurs ont formé des groupes de travail (GT) avec des patients à risque moyen figurant sur une liste d'attente de coloscopie de dépistage dans un établissement universitaire de coloscopie à fort débit. Pendant chaque séance de GT, on suscitait les commentaires au sujet d'une série de documents envisagés pour l'intervention planifiée au moyen d'un guide de facilitation semi-structuré. Les séances de GT ont été enregistrées et transcrites verbatim, puis ont été analysées au moyen de la méthode comparative constante pour déterminer les thèmes clés.

RÉSULTATS : Les observations tirées des trois GT $(n=28)$ laissaient supposer que les patients à risque moyen sur une liste d'attente de coloscopie de dépistage seraient réceptifs à une intervention ciblée recommandant qu'ils subissent une RSOS pendant cette attente. Les participants ont indiqué que l'invitation à subir une RSOS était une confirmation importante de leur présence sur une liste activement gérée et d'un mécanisme pour s'assurer d'un bon triage pendant l'attente. On a obtenu plusieurs suggestions précises en vue d'améliorer la conception de l'intervention ciblée.

CONCLUSIONS : Les résultats de la présente étude fournissent de l'information utile pour mettre au point des stratégies efficaces afin de gérer les personnes à risque moyen figurant sur de longues listes d'attente de coloscopie de dépistage.

provinces and internationally, have emphasized the fecal occult blood test (FOBT) as the primary screening test for average-risk adults (12).

However, increasing use of colonoscopy as a primary screening test for CRC $(13,14)$ creates challenges for FOBT-based provincial screening programs, and results in longer wait times for colonoscopy services (15). Indeed, there has been a huge demand for primary screening with colonoscopy in the Calgary (Alberta) area, in part fueled by the opening of a high-throughput academic outpatient colonoscopy facility in January 2008 (Forzani \& MacPhail Colon Cancer Screening Centre [CCSC] at the University of Calgary, Calgary, Alberta). The goal of the CCSC is to provide all CRC screening-related colonoscopies in the

\footnotetext{
${ }^{*}$ Co-first authors. ${ }^{1}$ Alberta Health Services - Cancer Care; ${ }^{2}$ Department of Community Health Sciences, Faculty of Medicine; ${ }^{3}$ Division of Preventive

Oncology, Department of Oncology, University of Calgary, Calgary, Alberta; ${ }^{4}$ School of Kinesiology and Health Science, York University; ${ }^{5}$ Population

Studies and Surveillance, Cancer Care Ontario; ${ }^{6}$ Dalla Lana School of Public Health, Faculty of Medicine, University of Toronto; ${ }^{7}$ Ontario Cancer

Institute, University Health Network; ${ }^{8}$ Department of Medicine, Faculty of Medicine, University of Toronto; ${ }^{9}$ Sunnybrook Health Sciences Centre;

${ }^{10}$ Institute for Clinical Evaluative Sciences, Toronto, Ontario; ${ }^{11}$ Division of Population Science, Thomas Jefferson University, Philadelphia,

Pennsylvania, USA; ${ }^{2}$ Department of Medicine, Faculty of Medicine, University of Calgary, Calgary, Alberta

Correspondence: Dr S Elizabeth McGregor, Population Health Research, Alberta Health Services - Cancer Care, 1331 29th Street Northwest, Calgary,

Alberta T2N 4N2. Telephone 403-521-3754,fax 403-270-8003, e-mail elizabeth.mcgregor@albertahealthservices.ca

Received for publication May 10, 2010. Accepted October 18, 2010
} 
Calgary area. Higher priority is given to patients referred for follow-up of a positive FOBT, previous CRC/polyps and/or family history of CRC/polyps. Receipt of more than 100 average-risk referrals per day has resulted in a substantial wait list, with the majority of average-risk patients waiting more than 18 months to undergo screening colonoscopy. Wait list management has become a major issue, and averagerisk patients are now recommended to undergo annual FOBT while waiting for their screening colonoscopy.

Patient reminders (eg, letters, postcards or telephone calls) can be effective in increasing screening uptake (16), and many populationbased programs include invitations targeted to eligible adults to increase FOBT uptake. The aims of the current study were to inform the content and design of a targeted mailed invitation to undergo an FOBT while awaiting colonoscopy, and to identify additional strategies for increasing FOBT uptake.

\section{METHODS}

Semistructured focus groups (FGs) were used to explore the reactions of screen-eligible adults to a range of possible materials (envelopes, letters, supplementary materials or FOBT kits) and strategies (eg, mailing FOBT kits directly to screen-eligible adults). All materials and strategies were under consideration for an intervention study to encourage average-risk adults to complete an FOBT while awaiting screening colonoscopy. Ethics approval was obtained from the Alberta Cancer Research Ethics Board and Conjoint Health Research Ethics Board of the University of Calgary.

\section{FG participants}

Three FG sessions, each $2 \mathrm{~h}$ in length, were conducted in Calgary in August 2009. Two single-sex FG sessions (one each of women only and men only) and one mixed-sex session were conducted. Participants were recruited using a mailed invitation to a random sample of average-risk patients on a wait list for screening colonoscopy. All patients had been referred to the CCSC by their primary care physician. FG participants received a small honorarium $(\$ 50)$ for participating in the session.

Each FG consisted of screen-eligible adults 50 years of age or older. The recruitment goals were a minimum of eight persons per group balanced according to age (younger than 65 years, and 65 years and older), employment status (working or retired/at home) and previous screening experience (screened or never screened). Informed consent was obtained by investigators before the actual sessions. All FGs were moderated by a psychologist (PR) with considerable experience in conducting qualitative interview studies.

\section{Materials tested \\ During each session, the moderator presented each component of the planned targeted intervention to FG participants in turn. Specific materials included the following: two versions of envelope return addresses (family physician or CCSC); three versions of invitation let- ters that varied in format and length; supplemental materials including two multipage brochures and a separate full-page fact sheet; and an instruction brochure. Materials were similar in content but varied in design, readability and style including layout, typeface and text density. A semistructured facilitator guide was used to elicit opinions and preferences regarding features that would prompt individuals to open and read the materials, help them comprehend key messages and persuade them to undergo an FOBT. Reactions to these materials allowed us to assess their openness and receptivity to undergoing an FOBT while on a wait list for a screening colonoscopy. In addition, the moderator sought responses to additional promotional strategies under consideration (media campaign, reminder card, follow-up telephone call, inclusion of FOBT kit and mailing instructions) to increase screening uptake.}

\section{Data analysis}

The demographic characteristics of the FG participants were tabulated. The FG sessions were recorded and transcribed verbatim. The constant comparative method was used to identify key themes
TABLE 1

Characteristics of focus group participants

\begin{tabular}{|c|c|c|c|c|}
\hline & \multicolumn{3}{|c|}{ Focus group } & \multirow[b]{2}{*}{ Total } \\
\hline & 1 & 2 & 3 & \\
\hline$n$ & 10 & 11 & 7 & 28 \\
\hline Men & $0(0)$ & $6(54)$ & $7(100)$ & $13(46)$ \\
\hline \multicolumn{5}{|l|}{ Age, years } \\
\hline $50-59$ & $6(60)$ & $5(45)$ & $3(43)$ & $14(50)$ \\
\hline $60-74$ & $4(40)$ & $6(55)$ & $4(57)$ & $14(50)$ \\
\hline \multicolumn{5}{|l|}{ Marital status } \\
\hline Married/common-law & $7(70)$ & $10(91)$ & $7(100)$ & $24(86)$ \\
\hline Divorced/separated & $2(20)$ & $1(9)$ & - & $3(11)$ \\
\hline Widowed & $1(10)$ & - & - & $1(4)$ \\
\hline \multicolumn{5}{|l|}{ Employment status } \\
\hline Working full-time & $5(50)$ & $4(36)$ & $4(57)$ & $13(46)$ \\
\hline Working part-time & $3(30)$ & - & $1(14)$ & $4(14)$ \\
\hline Retired & $2(20)$ & 7 (64) & $2(29)$ & $11(39)$ \\
\hline \multicolumn{5}{|l|}{ Education } \\
\hline High school or less & $2(20)$ & $3(27)$ & $3(42)$ & $8(29)$ \\
\hline Some postsecondary & - & $1(9)$ & - & $1(4)$ \\
\hline College/trade & $3(30)$ & $5(45)$ & $2(29)$ & $10(36)$ \\
\hline University & $5(50)$ & $2(18)$ & $2(29)$ & $9(32)$ \\
\hline \multicolumn{5}{|l|}{ Ancestry* } \\
\hline British & $4(40)$ & $6(54)$ & $3(43)$ & $13(48)$ \\
\hline European & $3(30)$ & $3(28)$ & $3(43)$ & $9(33)$ \\
\hline Other & $2(20)$ & $2(18)$ & $1(14)$ & $5(19)$ \\
\hline \multicolumn{5}{|l|}{ Screened for CRC? } \\
\hline Yes & $3(30)$ & $7(64)$ & $3(43)$ & $13(46)$ \\
\hline No & $7(70)$ & $4(36)$ & $4(57)$ & $15(54)$ \\
\hline \multicolumn{5}{|l|}{ CRC tests } \\
\hline FOBT only & $1(33)$ & $4(57)$ & $1(33)$ & $6(46)$ \\
\hline Colonoscopy only & $1(33)$ & - & $1(33)$ & $2(15)$ \\
\hline FOBT + colonoscopy & $1(33)$ & $2(29)$ & - & $3(23)$ \\
\hline FOBT + sigmoidoscopy & - & $1(14)$ & $1(33)$ & $2(15)$ \\
\hline
\end{tabular}

Data presented as $n$ (\%) unless otherwise indicated. *Data missing for one individual. CRC Colorectal cancer; FOBT Fecal occult blood test

representing varying attitudes and preferences, with the coding of the content of each FG performed on a line-by-line basis to identify all phrases, key words and expressed concepts (17). NVivo 8 (QSR International, USA) qualitative analysis software aided the process of coding the comparisons among the expressed concepts identified by participants.

\section{RESULTS}

FG invitation letters were sent to 150 individuals randomly selected from the wait list of adults 50 to 74 years of age referred by their family physician for average-risk screening colonoscopy in July 2010. Thirty-four persons responded to the invitation and 28 were available to attend one of the three FG sessions. The characteristics of the FG participants are summarized in Table 1.

Three broad themes emerged in the analysis of FG transcripts (Figure 1): openness to the intervention (directing attention to the mailed invitation package); engagement and decision making (considering the pros and cons of undergoing FOBT while wait-listed for colonoscopy); and addressing the practicalities of FOBT. A summary of the transcript analyses and illustrative quotes for each theme are provided below.

\section{Openness to the intervention}

A key underlying concept was the legitimacy of the source of the mailed invitation. The credibility and professionalism of materials were important in establishing this legitimacy, with FG participants highly suspicious of approaches that appeared 'mass produced' or 


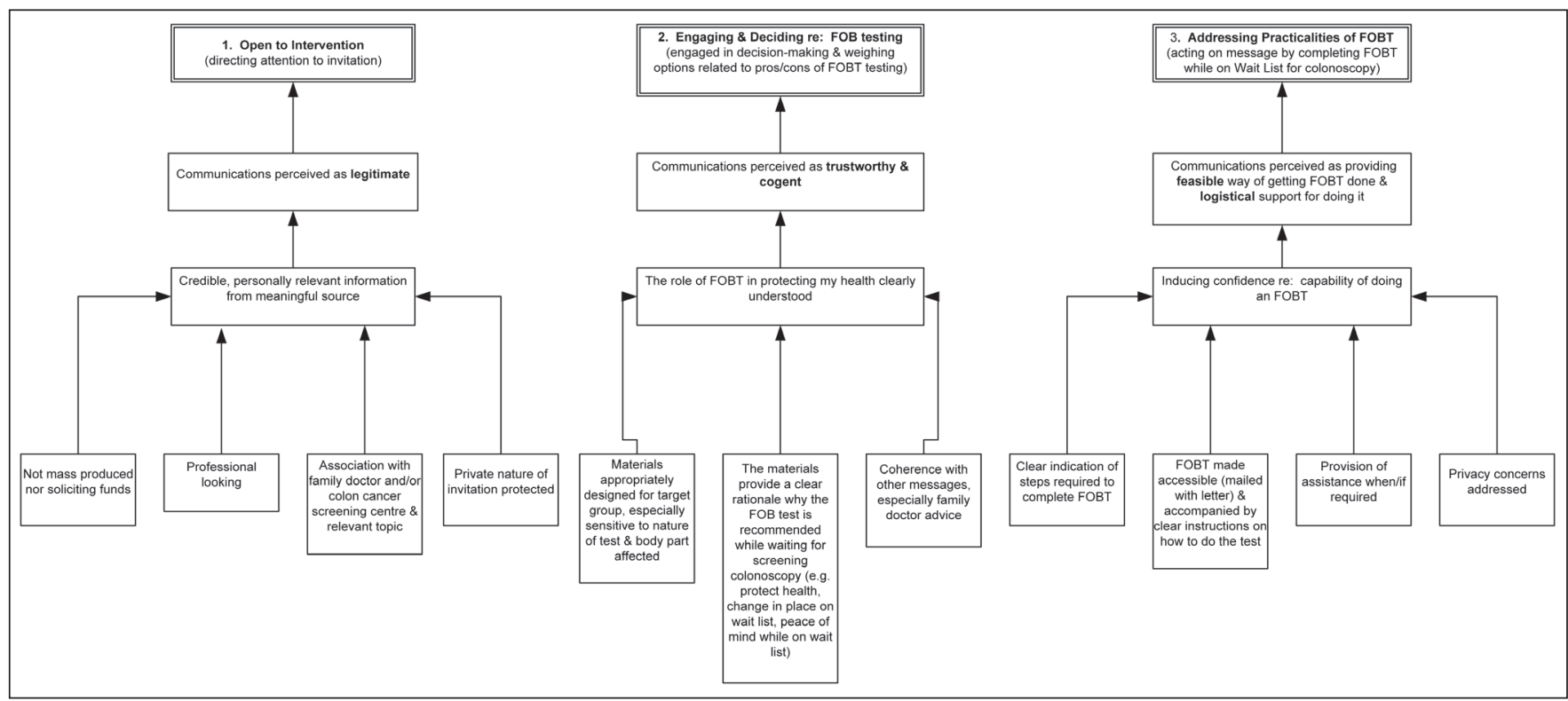

Figure 1) Coding tree summarizing the key themes and underlying concepts characterizing focus group participants' reactions to a targeted intervention recommending completing a fecal occult blood test (FOBT) while on a wait list for screening colonoscopy

resembled fundraising solicitations in any way. The perception that materials were personally relevant, largely through association with their family doctor, increased the likelihood that recipients would open the envelope to read the enclosed materials. Yet, for a minority of participants, a mailed invitation with their doctor's return address provoked anxiety or resulted in inattention because their doctorpatient communications usually occurred by telephone. Some participants voiced concerns about privacy issues and the sensitivity of the topic. These concerns may inform the optimal design of invitations and how the topic of colon cancer screening should be introduced.

For me, as soon as I saw this kind of a format I would throw it away, I wouldn't read it, because I get so many... (FG1 woman)

Something more professional, black and white, gets your attention and then a nice pamphlet...inside. I've read the letter. I know now this is a legit thing... (FG2 woman)

...If it just says, 'From your doctor to me', it's more personal and confidential... (FG2 man)

This one [from family doctor] I would open right away because I'd be worried, which is a motivating factor. (FG1 woman)

I think it will get tossed out because it's not going to be important, because the doctor would have told me. (FG3 man)

...It might be a little embarrassing for someone if another person in the family was to see this and go, 'Oh, my god. Are you having problems? Why do you need cancer screening? (FG2 man)

\section{Engagement and decision making}

Once FG participants were sufficiently engaged to open the invitation, the need to establish the intervention's connection with a trusted source was important. Brief letters with a clear purpose were more likely to be successful. Medical terminology was considered confusing or 'off-putting' by some, and special attention to the needs of people in the target age ranges (especially font size and literacy level) was considered to be important.

Invitation receipt soon after colonoscopy referral and coherence with other health messages also appeared to increase the likelihood of a positive response to materials. Participants believed that knowing how FOBT results would affect their colonoscopy wait time must be clearly conveyed. The variability in recommendations regarding FOBT received from family physicians was a source of confusion for some.

...When I see anything too lengthy, I lose interest... and it goes into the Blue Box [recycling bins]. (FG3 man)

...Cancer sort of leaps off the page because we have cancer in our family. That's the word that would speak to me. (FG1 woman)

...Some kind of name,... that conveys its purpose but doesn't involve fecal occult blood and all those things that are either misinterpreted, puts people off or whatever... (FG1 woman)

...Literacy level, of even the native Canadian people is quite low. Adult literacy is something like only 60 -some percent... keep it simple. (FG3 woman)

The letter could say 'You're on the waitlist for a colonoscopy. It's been our experience that if you do the stool sample test within the timeframe while you're waiting, that the chances are if there is a reason, boom, you're in. If there isn't, then just relax. We'll get to you'. It's a promise that you have been acknowledged. (FG2 woman)

...The best way... is for that letter to come to you pretty soon after you've talked to your doctor. ... (FG2 woman)

...Why didn't...[my doctor] send me for one of these [FOBT kits]? Why didn't he hand this to me five years ago? (FG1 woman)

...[My doctor] as an example, is not encouraging me to have this test $[\mathrm{FOBT}]$... any more. (FG3 man)

\section{Addressing the practicalities of completing the recommended FOBT}

All FG participants were receptive to completing an FOBT while on the wait list; however, many suggested that logistical support might be needed to complete the test. Receiving a mailed FOBT kit and instructions were considered to be helpful, but additional reminders received a mixed response, with some finding them helpful and others finding them intrusive. For some, the need for sensitivity and privacy for people needing assistance with testing was important. 
This [instruction pamphlet] has...a little bit more information about what you could do to actually collect...I think that one [pamphlet] said just collect a stool sample and you're...going, 'How am I supposed to do that?' (FG1 woman)

I think you'd get a better response if somebody sent it [the kit] to you. You think, 'Ah, what the hell? I might as well do it'. (FG2 man)

...I thought this [reminder] letter was pressuring me...I don't need a reminder, I....would resent it. (FG1 woman)

I like [the letter] because it has a WWW number...If you wanted to check on the internet in private for a little bit more information, I think that would help me a lot. (FG2 woman)

\section{DISCUSSION}

The FG findings suggest that average-risk patients wait-listed for screening colonoscopy were receptive to a targeted intervention recommending they undergo an FOBT while waiting. The explicit invitation to undergo FOBT appeared to serve the following three functions: clear confirmation that they were on the wait list (for colonoscopy); a mechanism was in place to ensure that they were correctly triaged while they were waiting; and, for some, the potential for moving up the list if their FOBT was positive. FG findings provided several useful improvements for the design of the targeted intervention, which included the following: sending the invitation letter to patients soon after their referral for colonoscopy such that the referral 'primes' them to respond to the targeted FOBT uptake intervention; clearly indicating how the FOBT result will affect their position on the wait list; positioning the message as a step they can take to protect themselves while awaiting colonoscopy; including the FOBT kit and supportive materials in the targeted intervention; and acknowledging the role of their family doctor as their partner in care. The need to work closely with family physicians is highlighted by findings suggesting that lack of consistent messages regarding FOBT (as a reasonable way to screen for $\mathrm{CRC}$ ) is a source of confusion for patients and may reduce the willingness of patients to consider FOBT while on the wait list.

The findings of Calgary FGs were very consistent with FGs conducted in Ontario (18) and other FG findings (19-22) including the key role of the family physician and the need to address sensitivity concerns (23). Support for the use of multiple channels ('priming') is consistent with other FGs (24) and studies showing that advance notification letters increased compliance (25).

Public interest in cancer screening is high (26), but understanding of screening is low, particularly with respect to the need for testing in the absence of symptoms (27). CRC, with its multiple options for testing, presents further challenges for those providing education about screening. The receptivity of our FG participants to a recommendation for essentially an 'interim' test among a group of patients referred for what some may consider to be the 'gold standard' test was somewhat unexpected. However, many FG participants were not familiar with FOBT, and may not be sufficiently familiar with FOBT and/or colonoscopy to understand the different benefits and risks of these two tests. Thus, they may consider completing an FOBT while waiting for a screening colonoscopy to simply be part of an overall CRC screening care program.

We did not ask FG participants about their future intentions to complete the screening colonoscopy for which they were initially referred once the FOBT was completed, and cannot speculate as to how the recommendation to undergo an FOBT while waiting may affect compliance with the colonoscopy originally recommended by their family physician. It is possible that some average-risk adults may prefer FOBT to colonoscopy for CRC screening (28-30). Individuals may weigh various features of FOBT versus colonoscopy differently than physicians in making decisions about what type of CRC screening they prefer $(31,32)$. Similarly, the type of information considered to be important in facilitating informed choices about CRC screening may differ among the public, health policy makers and health care providers $(33,34)$.
There are several limitations of the present study that may affect the generalizability of the findings. FG participants were recruited from the wait list of a single outpatient academic colon cancer screening centre and may not reflect the views held in other geographical locations. The sample was primarily of British/European descent and English speaking; thus, the findings may not be generalizable to other ethnic groups and cultures. Low literacy groups may also have different information needs and sensitivities regarding FOBT (35). All FG participants had been referred by their primary care physician for CRC screening and are, thus, likely a select group in terms of health motivation and openness to screening as a health protective measure. The findings may not be generalizable to the public who have not already accepted a referral for CRC screening.

Opportunistic colonoscopy screening of average-risk adults is occurring with increasing frequency despite the implementation of population-based home FOBT programs. Pressures on colonoscopy capacity are likely to increase as demand for primary colonoscopy screening increases in conjunction with efforts to increase CRC screening with stool tests. Results of the present study provide useful information for developing effective strategies to deal with the emerging clinical issue of average-risk individuals facing long wait times for screening colonoscopy.

\section{SUMMARY}

Population-based efforts to increase CRC screening rates combined with limited capacity has resulted in long wait times for averagerisk adults referred for screening colonoscopy. Findings from three FGs suggest that average-risk patients on a wait list for screening colonoscopy would be receptive to a targeted intervention recommending they undergo an FOBT while waiting for their screening colonoscopy. The present study provides useful information for developing effective strategies to deal with the emerging clinical issue of average-risk individuals facing long waits for screening colonoscopy.

ACKNOWLEDGEMENTS: This work was also supported by a grant from the Canadian Institutes for Health Research Team in Populationbased Colorectal Cancer Screening (grant \# CST-85478). The authors thank Janine English for her assistance with the focus groups.

\section{REFERENCES}

1. Canadian Cancer Society's Steering Committee. Canadian Cancer Statistics 2010. Toronto: Canadian Cancer Society, 2010.

2. Shapiro JA, Seeff LC, Thompson TD, Nadel MR, Klabunde CN, Vernon SW. Colorectal cancer test use from the 2005 National Health Interview Survey. Cancer Epidemiol Biomarkers Prev 2008;17:1623-30

3. McGregor SE, Hilsden RJ, Li FX, Bryant HE, Murray A. Low uptake of colorectal cancer screening $3 \mathrm{yr}$ after release of national recommendations for screening. Am J Gastroenterol 2007;102:1727-35.

4. Rabeneck L, Paszat LF. A population-based estimate of the extent of colorectal cancer screening in Ontario. Am J Gastroenterol 2004;99:1141-4.

5. Wilkins K, Shields M. Colorectal cancer testing in Canada - 2008. Health Reports 2009;20:1-10.

6. U.S. Preventive Services Task Force. Screening for colorectal cancer: Recommendation and rationale. Ann Intern Med 2002;16:129-31.

7. Screening for colorectal cancer: U.S. Preventive Services Task Force recommendation statement. Ann Intern Med 2008;149:627-37.

8. Canadian Task Force on Preventive Health Care. Colorectal cancer screening. Recommendation statement from the Canadian Task Force on Preventive Health Care. CMAJ 2001;165:206-8.

9. Winawer S, Fletcher R, Rex D, et al. Colorectal cancer screening and surveillance: Clinical guidelines and rationale - update based on new evidence. Gastroenterology 2003;124:544-60.

10. Levin B, Lieberman DA, McFarland B, et al. Screening and surveillance for the early detection of colorectal cancer and 
adenomatous polyps, 2008: A joint guideline from the American Cancer Society, the US Multi-Society Task Force on Colorectal Cancer, and the American College of Radiology. Gastroenterology 2008; 134:1570-95.

11. Leddin D, Hunt R, Champion M, Cockeram A, Flook N. Canadian Association of Gastroenterology and the Canadian Digestive Health Foundation: Guidelines on colon cancer screening. Can J Gastroenterol 2004;18:93-9.

12. National Cancer Institute. International Cancer Screening Network. Inventory of colorectal cancer screening activities in ICSN countries, May 2008. National Cancer Institute 2010 <http://appliedresearch.cancer.gov/icsn/colorectal/screening.html> (Accessed on March 4, 2011).

13. Phillips KA, Liang SY, Ladabaum U, et al. Trends in colonoscopy for colorectal cancer screening. Med Care 2007;45:160-7.

14. Shapiro JA, Seeff LC, Thompson TD, Nadel MR, Klabunde CN, Vernon SW. Colorectal cancer test use from the 2005 National Health Interview Survey. Cancer Epidemiol Biomarkers Prev 2008;17:1623-30.

15. Armstrong D, Barkun AN, Chen Y, et al Access to specialist gastroenterology care in Canada: the Practice Audit in Gastroenterology (PAGE) Wait Times Program. Can J Gastroenterol 2008;22:155-60.

16. Baron RC, Rimer BK, Breslow RA, et al. Client-directed interventions to increase community demand for breast, cervical, and colorectal cancer screening: A systematic review. Am J Prev Med 2008;35(Suppl 1):S34-S55.

17. Flick U. An introduction to qualitative research, $3 \mathrm{rd}$ edn. Thousand Oaks: SAGE Publications, 2006.

18. Timouth J, Ritvo P, McGregor SE, et al. A qualitative evaluation of stratgies to increase colorectal cancer screening uptake. Can Fam Physician 2011;57:e7-15.

19. Ornstein SM, Musham C, Reid A, Jenkins RG, Zemp LD, Garr DR. Barriers to adherence to preventive services reminder letters: The patient's perspective. J Fam Pract 1993;36:195-200.

20. Ornstein SM, Musham C, Reid AO, Garr DR, Jenkins RG, Zemp LD. Improving a preventive services reminder system using feedback from focus groups. Arch Fam Med 1994;3:801-6.

21. Kaczorowski J, Karwalajtys T, Lohfeld L, et al. Women's views on reminder letters for screening mammography: Mixed methods study of women from 23 family health networks. Can Fam Physician 2009;55:622-3.

22. Karwalajtys T, Kaczorowski J, Lohfeld L, et al. Acceptability of reminder letters for Papanicolaou tests: A survey of women from
23 family health networks in Ontario. J Obstet Gynaecol Can 2007;29:829-34.

23. O'Sullivan I, Orbell S. Self-sampling in screening to reduce mortality from colorectal cancer: A qualitative exploration of the decision to complete a faecal occult blood test (FOBT). J Med Screen 2004;11:16-22.

24. Holt CL, Shipp M, Eloubeidi M, et al. Use of focus group data to develop recommendations for demographically segmented colorectal cancer educational strategies. Health Educ Res 2009;24:876-89.

25. Cole SR, Smith A, Wilson C, Turnbull D, Esterman A, Young GP. An advance notification letter increases participation in colorectal cancer screening. J Med Screen 2007;14:73-5.

26. Schwartz LM, Woloshin S, Fowler FJ Jr, Welch HG. Enthusiasm for cancer screening in the United States. JAMA 2004;291:71-8.

27. Cockburn J, Redman S, Hill D, Henry E. Public understanding of medical screening. J Med Screen 1995;2:224-7.

28. DeBourcy AC, Lichtenberger S, Felton S, Butterfield KT, Ahnen DJ, Denberg TD. Community-based preferences for stool cards versus colonoscopy in colorectal cancer screening. J Gen Intern Med 2008;23:169-74.

29. Almog R, Ezra G, Lavi I, Rennert G, Hagoel L. The public prefers fecal occult blood test over colonoscopy for colorectal cancer screening. Eur J Cancer Prev 2008;17:430-7.

30. Marshall DA, Johnson FR, Phillips KA, Marshall JK, Thabane L, Kulin NA. Measuring patient preferences for colorectal cancer screening using a choice-format survey. Value Health 2007;10:415-30.

31. Ling BS, Moskowitz MA, Wachs D, Pearson B, Schroy PC. Attitudes toward colorectal cancer screening tests. J Gen Intern Med 2001;16:822-30.

32. Hawley ST, Volk RJ, Krishnamurthy P, Jibaja-Weiss M, Vernon SW, Kneuper $S$. Preferences for colorectal cancer screening among racially/ethnically diverse primary care patients. Med Care 2008;46(9 Suppl 1):S10-S16.

33. Jepson RG, Hewison J, Thompson A, Weller D. Patient perspectives on information and choice in cancer screening: A qualitative study in the UK. Soc Sci Med 2007;65:890-9.

34. Woodrow C, Watson E, Rozmovits L, Parker R, Austoker J. Public perceptions of communicating information about bowel cancer screening. Health Expect 2008;11:16-25.

35. Dolan NC, Ferreira MR, Davis TC, et al. Colorectal cancer screening knowledge, attitudes, and beliefs among veterans: Does literacy make a difference? J Clin Oncol 2004;22:2617-22. 


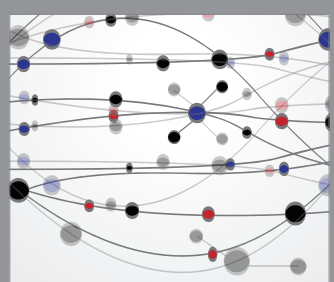

The Scientific World Journal
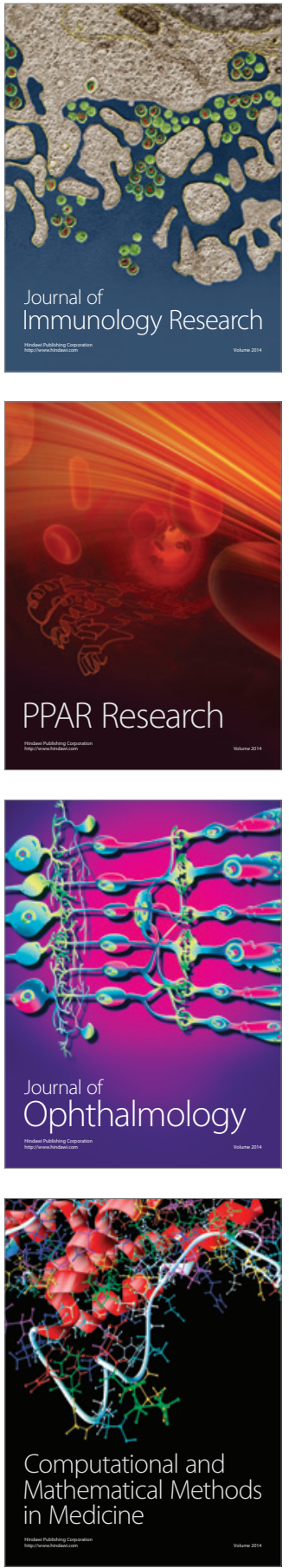

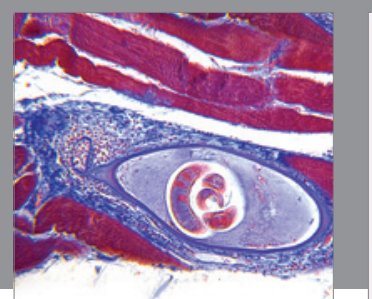

Gastroenterology Research and Practice

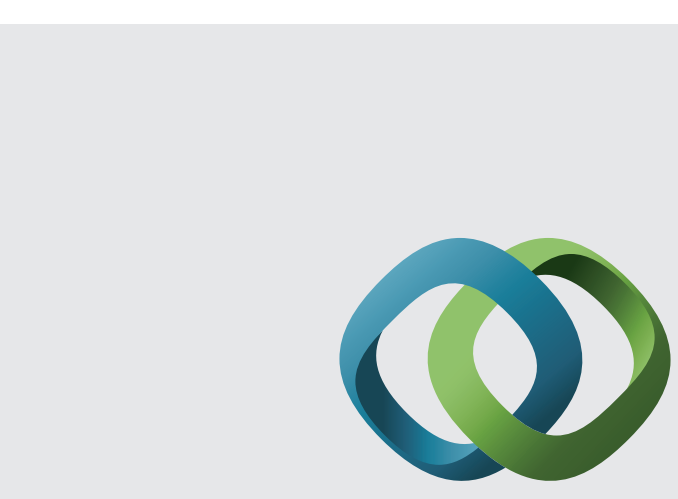

\section{Hindawi}

Submit your manuscripts at

http://www.hindawi.com
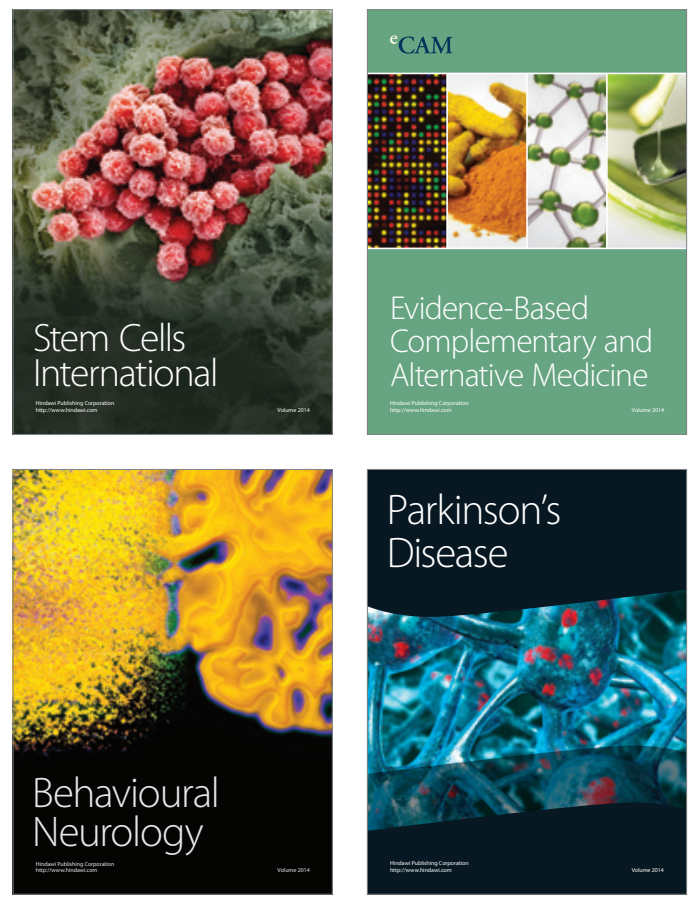
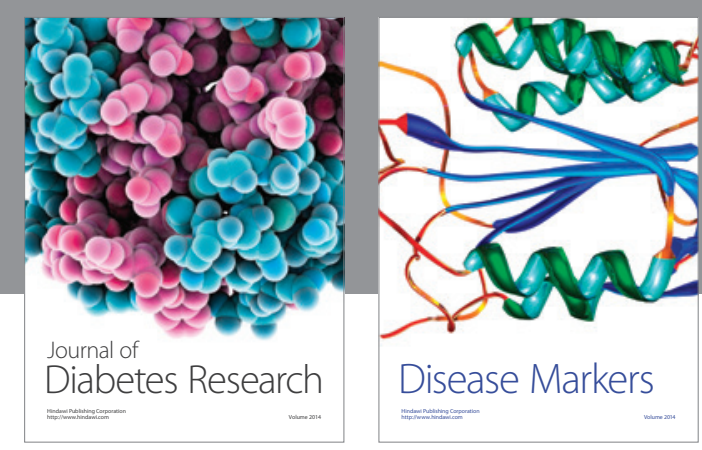

Disease Markers
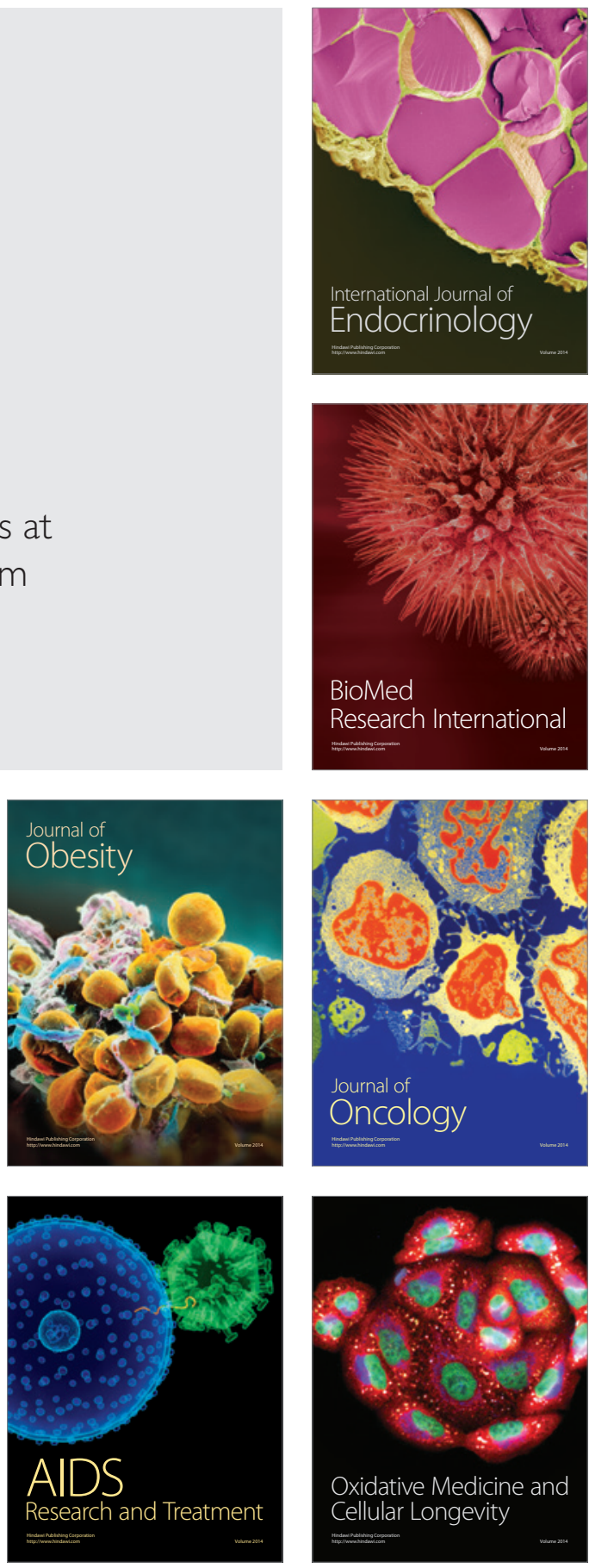